Editorial

\title{
La praxis consciente de resiliencia en el contexto pandémico
}

\section{The conscious practice of resilience in the pandemic context}

\author{
Martínez Báez, Francisco
}

\author{
Francisco Martínez Báez \\ frankartista@hotmail.com \\ Universidad Nacional Autónoma de Nicaragua, \\ Managua. Músico, Culturólogo e Historiador del Arte, \\ Nicaragua
}

\section{Revista Torreón Universitario}

Universidad Nacional Autónoma de Nicaragua-Managua,

Nicaragua

ISSN: 2410-5708

ISSN-e: 2313-7215

Periodicidad: Cuatrimestral

vol. 10, núm. 27, 2021

revis.torreon.faremc@unan.edu.ni

\section{URL: http://portal.amelica.org/ameli/}

jatsRepo/387/3871840013/index.html

DOI: https://doi.org/10.5377/torreon.v10i27.10833

\begin{abstract}
El autor o los autores de los artículos, ensayos o investigaciones conceden a la Universidad Nacional Autónoma de Nicaragua, Managua (UNAN-Managua) los derechos de edición (copyright) del trabajo enviado, por consiguiente la Universidad cuenta con el derecho exclusivo para publicar el artículo durante el periodo completo de los derechos de autor.
\end{abstract}

\section{(c) $(1) \Theta(\Theta$}

Esta obra está bajo una Licencia Creative Commons AtribuciónNoComercial-SinDerivar 4.0 Internacional.

A lo largo de la historia la humanidad ha afrontado centenares de pandemias, desde la plaga de Atenas en el año 430 a. C, hasta el Covid-19 en el siglo XXI. Todas las pandemias son letales cuando una persona está desinformada. El problema de este siglo son las teorías conspirativas, así como la producción y el consumo de noticias falsas. Es por ello que se hace necesario el pensamiento crítico para distinguir la información verídica y exacta, de aquella que es falsa. En la era de la comunicación, la información y el conocimiento es necesario aprender a seleccionar adecuadamente las fuentes informativas sobre el COVID19, ya que, de lo contrario, podemos caer en la infodemia, lo cual significa según la OMS, la búsqueda de fuentes no oficiales sobre el origen del virus, por un lado y de otro, el contagio y tratamiento no correcto de la enfermedad" (Fernández, 2020, p. 35).

Como hemos dicho antes, la humanidad ha logrado sobrevivir diversas situaciones extremas como las guerras, los desastres naturales y las pandemias. En los conflictos armados, las partes contendientes saben con 
quienes se enfrentan y cómo afrontarlo; los desastres naturales como la sequía suelen llegar casi sin previo aviso; ¿y las enfermedades?

En la antigüedad la lepra fue una de las enfermedades más temibles y hasta percibida con cierto terror social, muchas veces los que enfermaban estaban condenados al distanciamiento social severo. Es decir, el destierro total junto con la feroz etiqueta social condenatoria, la que era atribuida a hechicerías, castigo divino, malos espíritus, etc. Según Zulueta: "Desde tiempos muy remotos y en todas las culturas, esta enfermedad ha despertado imágenes especiales de horror, miedo, repulsión, asquerosidad y estigma íntimamente asociado a ella" (pág.181).

En la Edad Media la peste bubónica o peste negra, fue llamada así, no solo por la época oscura teocéntrica y toda la cultura de la muerte que existía, como la “...relación de los hombres con la propia muerte y la relación de los vivos con los muertos marcaron la sociedad medieval con una multiplicidad de actitudes y reacciones, traducidas con frecuencia a través de la imagen” (Jouan \& Souz, 2018, p. 239). Esta percepción colectiva reforzaba el mito de ultramundos, especialmente en el moribundo, en cuya patología destilaba hemorragias en la piel de color negro, y la inminente fatalidad. «[Esta] ... epidemia que asoló a mediados del siglo XIV los países mediterráneos, y en concreto a Europa, produjo tasas de mortalidad que fueron superiores a las de cualquier otra peste, ya que se difundió a gran velocidad», según Gómez y Moclán. La peste bubónica causó estragos de gran magnitud, al grado de causar más de veinticinco millones de muertos; la mitad de la población europea. Ninguna guerra había causado todavía semejante hecatombe. La dimensión de esa plaga fue metafísica, y considerada por el pensamiento de la época, como expresión del castigo de la ira divina, (Deville, 2012).

Antropólogos forenses, arqueólogos e historiadores han identificado a la peste bubónica del siglo XIV como causal de la muerte de cuerpos enterrados hace 3800 años. Esta cepa es la más antigua y es la misma que para algunas de las epidemias más mortíferas de nuestra historia. La peste justiniana (541-543) fue la primera pandemia con reporte de los bubones típicos y ocurrió durante el gobierno de Justiniano I. Luego vino la plaga de China entre 1890 hasta 1910.

El suplicio de las pandemias no solo termina en el siglo XIX, sino que continua en el siglo XX con la Gripe Española de 1918, considerada como la más devastadora de la historia. Se estima que afectó a un tercio de la población mundial, y más del $2.5 \%$ de los enfermos murieron. Esta pandemia, según Lüthy, Viviana y Kantor se presentó en dos oleadas principales: 1918 y 1919, y fue causada por un brote del virus de la gripe tipo A, subtipo H1N1. Durante los cuatro años que duró el conflicto de la Primera Guerra Mundial murieron 10 millones de personas; paradójicamente, según Carmona y Tribiño, desde la primavera hasta el otoñoinvierno de 1918, cuando se extendió por todo el mundo una pandemia de gripe con tal gravedad y letalidad, se calcula que causó entre 25 a 65 millones de muertos.

Nicaragua en el S. XIX padeció de una devastadora epidemia. En el testimonio, de 1886, C. W. Doubleday sostiene que, en la Guerra Filibustera de 1854, el cólera asiático apareció con una violencia que era sin duda a causa de la deficiencia en regulaciones sanitarias (...) Los muertos en los diversos encuentros de los alrededores de la ciudad eran dejados para que fueran pastos de los zopilotes, los que volaban constantemente en grandes bandales que cubrían el aire. En el libro titulado Managua a través de la historia, 1846-1946, de Gratus Halftermeyer, se manifiesta que en 1854 apareció el cólera morbus en Managua; pero fue la invasión de Walker y la Guerra Nacional que derramó mucha sangre de hermano. En aquella época, se enterraba a los muertos sin los protocolos mortuorios, algunas veces por miedo a ser contagiado y otras, debido al alto número de víctimas. En ese tiempo no había un sistema sanitario adecuado, Managua apenas había sido elevada a ciudad en 1846 y el 5 de febrero de 1852 como Capital de la Republica de Nicaragua.

¿Cómo los nicaragüenses hemos afrontados las adversidades? Esa capacidad resiliente se va construyendo para resistir a medida que las dificultades se han aparecido en el camino. Podemos preguntar: ¿Qué podemos hacer para no estar deprimidos? ¿Cómo hacer para que las medidas de distanciamiento social no impidan la expresión afectiva? Cuando en verdad estamos acostumbrados de darnos un abrazo o estrechamos nuestras 
manos, nos comunicamos con la otra persona. "Nos comportamos como si nuestra reserva de signos de reconocimiento fuera limitada cuando, de hecho, es inagotable, y los distribuimos con especial parsimonia, ya que son los más agradables de recibir" (Gisbert \& Cuadra, 1996, p. 130) ¿qué hacer en los próximos años, si el COVID19 persiste? de hecho, hay más preguntas que respuestas porque el futuro suele ser incierto.

El acto de bienvenida del tercer milenio para el mundo global, en el que estamos todos inmersos, atraviesan un tiempo no ordinario, en cierto modo comparable a los resultados de las grandes conmociones bélicas del siglo XX. Antes de la pandemia, se observa una crisis de la civilización occidental, la cual tiene su expresión en los aspectos planetarios, demográficos, económicos y de convivencia entre los seres humanos. Puede que hayamos perdido el sentido de vida y que todo esté ensombrecido, pero los seres humanos tienen capacidad de adaptación, a ello le llamamos la resiliencia, que es la capacidad de recuperación, siempre y cuando haya en el individuo una determinación inquebrantable.

La pandemia nos invita a reflexionar sobre nuestro modelo de desarrollo. De igual modo nos enseña que algunos componentes fundamentales del bienestar espiritual, si se descuidan se convertirán en puntos débiles y vulnerables con consecuencias sociales, económicos y de convivencia que ocurren cuando el sistema es sometido a un choque. Tenemos que promover el desarrollo humano, basado en la creatividad y la innovación que nos ayude a encontrar respuestas ante los retos que vivimos, especialmente con respecto a la educación.

$\mathrm{Al}$ poner el foco en el nivel socio-histórico, el modelo de resiliencia nos ofrece una explicación del fenómeno, por el cual un sujeto comunitario revela una mayor capacidad de superación de traumas que un sujeto individual, la ..." resiliencia nace en la física para referirse a la capacidad de los cuerpos de resistir los impactos y volver a su forma inicial, y ha sido adoptado por las Ciencias Sociales" (Pinto, 2014, p. 20).. No es casualidad que aplicado a una comunidad y no a un solo individuo, el concepto de resiliencia esté ganando terreno en el análisis de las dinámicas sociales de grupos o comunidades afectadas por desastres naturales o por eventos producidos por la acción humana como crisis, enfermedades, conflictos sociales o guerras. Los resultados de algunas investigaciones destacan cómo la mayor o menor resiliencia ante eventos traumáticos produce efectos diferentes o incluso opuestos en las comunidades menos resilientes, y por tanto más frágiles, como consecuencia del trauma constituido por una catástrofe. Estas comunidades, dejan de desarrollarse permaneciendo en una situación de inestabilidad permanente o en algunos casos, incluso colapsan. Los grupos sociales resilientes, por otro lado, sobreviven o incluso aprovechan la oportunidad del trauma como una oportunidad para regenerarse, fortalecerse y comenzar un nuevo ciclo de vida.

En el plano educativo, es cierto que en la universidad se están sintiendo las consecuencias de la pandemia de COVID-19. Esta nueva enfermedad ha significado dolor y luto ante la partida de amigos y familiares, pero también un reto para adaptarnos a las nuevas circunstancias. El jurista y filósofo romano Marcos Tulio Cicerón (106 a.C- 43 a.C), decía que "la vida de los muertos perdura en la memoria de los vivos". A consecuencia de ello, las instituciones de educación superior -especialmente las estatales- tuvieron que reaccionar rápidamente con la implementación de un protocolo de bioseguridad, para aplicar distintas medidas: toma de temperatura, lavado constante de manos, distanciamiento físico entre otras, las cuales son necesarias para controlar la propagación del virus. Ello ha contado con la participación e involucramiento de toda las autoridades y la comunidad universitaria, quienes se han dispuesto para cuidar y proteger la vida de todos sus miembros.

En las tales circunstancias la universidad se planteó una solución ¿cómo hacer para atender a los estudiantes, y que no perdieran su año lectivo? Más allá de los cambios en las prácticas de enseñanza y las evaluaciones, imaginar las muchas consecuencias que las medidas de distanciamiento físico pueden tener en los actores de la educación superior: estudiantes, profesores y administradores. Así, la respuesta eficaz de la UNAN-Managua ha permitido definir nuevas estrategias didácticas, la adecuación curriculary la redefinición de horarios, asignaturas integradas y las orientaciones metodológicas en línea, todo ello con el fin de generar creativamente estrategias de resiliencia en los mismos actores. 
Por otro lado, se han publicado numerosos reportes en los medios de comunicación social, pero, hasta la fecha, son escasas las investigaciones sobre efectos de COVID-19 en la educación superior, que podría proporcionar evidencia sobre las mejores prácticas adoptadas: ¿cuáles han sido los efectos de la pandemia en las estrategias de evaluación de enseñanza y aprendizaje implementadas?, ¿cuáles fueron los retos encontrados y las oportunidades que han surgido en el proceso de estudios en la educación superior?

Siempre habrá preguntas que no podemos responder con precisión, entonces ¿será que el coronavirus es quién dicta las reglas?, ¿determina el comportamiento social? ¿es que la epidemia ha cambiado nuestra concepción con la muerte? No podemos dejarnos atrapar por la desesperanza, ni tampoco por el negativismo. La resiliencia nos ayuda a encontrar el camino para destacar nuestras fortalezas como miembros de una sociedad, para sobreponernos a los desafíos que la vida nos plantea. Con ese espíritu de lucha frente a la adversidad, podremos vencer el pesimismo, la angustia, la desesperanza que muchos pregonan en estos días. Friedrich Hebbel decía: "Hay personas que se consolarían hasta del fin del mundo, con tal de que ellas lo hubiesen anunciado".

\section{REFERENCIAS}

Arvide Cambra, L. M. (2013). Prescripciones médicas de IBN Jatima para el tratamiento paliativo en la enfermedad de la Peste Bubónica. European Scientific Journal, edition vol.9, No.18, 13-19.

Carmona Barrero, J. D., \& Tribiño García, M. (2019). Almendralejo y Tierra de Barrosen el primer tercio del Siglo XX (1898-1931). Actas de las X Jornadas de Historia de Almendralejo y Tierra de Barros. Almendralejo y Tierra de: Impresores de Almendralejo, S. L.

Deville, P. (2012). Peste \& Cólera. (T. d. Fajardo, Trad.) Barcelona (España): Editorial Anagrama.

Doubleday, W. (1886). La Guerra Filibustera en Nicaragua. MANUEL GRANIZO, 1-44.

Fernández Poncela, A. M. (2020). Infodemia: rumores, fake news, mitos. Sintaxis. Revista cientifica del Centro de Investigación para la Comunicación Aplicada, Año 2, 35-55.

Gisbert, J., \& Cuadra, J. (1996). The caresses in the class-room. Enseñanza de las Ciencias de la Tierra, (4.2),, 130-132.

Gómez Miguelsanz, C., \& Moclán Ramos, A. (2 de octubre de 2012). La Peste Negra. Madrid.

Haindl U., A. L. (25 de septiembre de 2013). La Peste Negra.

Halftermeyer, G. (1946). Managua a través de la historia, 1846-1946. Managua: Hospicio.

Hernández-Mesa, N., Hernández Llanes, J., \& Betancourt, L. (2000). Las grandes epidemias de la Historia. De la peste de Atenas a la COVID-19. Revista Habanera de Ciencias Médicas, Caridad, 1-13.

Jouan Dias, C., \& Souz, A. d. (2018). Muerte y representación en la Edad Media: consideraciones sobre la imagen, la iconografía de la muerte y la influencia de la Peste Negra en el surgimiento de los temas macabros. Miscelánea, 239-258.

Lüthy, S. A., Viviana, R., \& Kantor, I. N. (2018). A Cien Años de la Gripe "Española. MEDICINA (Buenos Aires) No. $78,113-118$.

Pinto Cortez, C. (2014). Resiliencia psicológica:una aproximación hacia su conceptualización, enfoques teóricos y relacióncon el abuso sexual infantil. SUMMA Psicológica UST, Vol. 11, №2, , 19-33.

Zulueta R, A. M. (1994). Evolución histórica, epidemiologia y medidas de control. Dermatología Venezolana, vol. 32, $\mathrm{n}^{\circ} 4$ año, 181-190. 